\title{
Process chain for the fabrication of hardenable aluminium- zirconium micro-components by deep drawing
}

\author{
Anastasiya Toenjes ${ }^{1,}$, , Julien Kovac ${ }^{1}$, Bernd Koehler ${ }^{1}$, Axel von Hehl ${ }^{1,2}$, Andreas Mehner ${ }^{1,2}$, Brigitte Clausen ${ }^{1,2}$ and Hans- \\ Werner Zoch ${ }^{1,2}$ \\ ${ }^{1}$ Leibniz Institute for Materials Engineering IWT, 28359 Bremen, Germany \\ ${ }^{2}$ MAPEX Center for Materials and Processing \\ 1,2,University of Bremen, Faculty of Production Engineering, 28359 Bremen, Germany
}

\begin{abstract}
Today, micro components are used in various industrial sectors such as electronics engineering and medical applications. The final quality of such parts depends on each individual step of the production chain from the manufacturing of semi-finished parts to the post-processing. In this study, magnetron sputtering is used to manufacture thin $(15-30 \mu \mathrm{m})$ aluminium-zirconium alloy foils for the deep drawing of high strength and hardenable micro cups, which can be, for example, employed as micro valve caps. The development of a novel process chain for the production of these parts includes four different steps, beginning with the production of $\mathrm{Al}-\mathrm{Zr}$ foils by magnetron sputtering. Secondly, tensile tests are performed with the foils in order to estimate their mechanical properties. Subsequently, micro deep drawing is used to produce the cup's shape, and finally, a heat treatment in a drop-down tube furnace adjusts the cup's hardness during fall. It is shown in particular that $\mathrm{Al}-\mathrm{Zr}$ foils produced by magnetron sputtering have an attractive cold forming and hardening potential due to a microstructure consisting essentially of an oversaturated solid solution of zirconium in the aluminium matrix. This material state enables adequate formability and simplifies the heat treatment process since no solution annealing is required.
\end{abstract}

Keywords: Cold forming, Material, Development.

\section{Introduction}

The trend for micro components in various applications such as medical tools, connectors in mobile phones or fuel injectors requires a decrease of size and an increase in quality over the whole product life cycle. At the same time, the relation between quality of parts, production speed and cost must be balanced. To fulfil these requirements, new production technologies, materials and testing methods are necessary because direct downscaling of processes for macro parts into the micro scale is rarely possible.

In this paper, four steps for the development of a process chain for the production of micro cold-formed cups made of a high-strength aluminium alloy are presented. Among the possible alloying elements for aluminium to increase the hardness, scandium shows the best potential due to the formation of nanoscaled cubic ( $\mathrm{L}_{2} \mathrm{Cu}_{3} \mathrm{Au}$-type) $\mathrm{Al}_{3} \mathrm{Sc}$ precipitates. These equilibrium precipitates provide an extraordinarily high lattice misfit without losing the coherence with the aluminium matrix and, hence, result in a significantly higher strength of the alloy compared to semi-coherent precipitates in conventionally age-hardened alloys [1]. However, the limited availability of scandium increases the cost of parts and makes the industrial use of such alloys difficult. Alternatively, other alloying elements such as zirconium in combination with the base material aluminium lead to similar effects based on the formation of zirconium tri-aluminide precipitates $\left(\mathrm{Al}_{3} \mathrm{Zr}\right)$ [2]. In order to enable high deep drawing ratios, the precipitates should only be formed after the deep drawing process. Indeed, the presence of precipitates in the material before cold forming would result in a limited ductility. Therefore, any post forming heat treatment must be performed on a material that is free of precipitates at this point in the process chain.

Due to high processing temperatures and low solidification and cooling rates during conventional slab casting of $\mathrm{Al}-\mathrm{Zr}$ alloys it is not possible to obtain more than 0.28 wt. \% zirconium in the solid solution with the aluminium. The binary Al-Zr phase diagram shows that the maximum solubility of zirconium in aluminium is only 0.28 wt. $\%$ at the melting point $\left(650^{\circ} \mathrm{C}\right)$ [3]. As shown in our previous work, magnetron sputtering enables the fabrication of thin foils with a thickness of $15-30 \mu \mathrm{m}$ containing up to $4 \mathrm{wt}$. \% zirconium in supersaturated solid solution [4-5]. The properties of these foils, i.e. semi-finished products for cold forming, depend on several parameters of the magnetron sputtering process, primarily the target power.

Thus, the mechanical properties of the cold formed components depend on the initial state of the semifinished products since the forming parameters affect

* Corresponding author: toenjes@,iwt-bremen.de 
strain hardening of the material during cold forming and the ageing behavior during subsequent heat treatment. By means of the heat treatment process, the resulting mechanical properties have to be adjusted to the application specific requirements.

The objective of this study is the investigation of the influence of the processing parameters of each step of the process chain on the mechanical properties of the resulting components. The mechanical properties of the semi-finished components were tested by tensile tests and micro hardness measurements. The mechanical properties of deep drawn cup before and after the heat treatment were also investigated by the micro hardness.

\section{Fabrication of thin Al-Zr alloy foils by magnetron sputtering}

\subsection{Working principle of magnetron sputtering}

Magnetron sputtering is a frequently used physical vapour deposition (PVD) process for the deposition of functional thin films or coatings. The most common applications of this technology is the deposition of hard coatings for cutting and forming tools, coatings for wear and corrosion protection, low friction coatings as well as conducting and semiconducting coatings for microelectronic devices and photovoltaic cells or special biocompatible coatings for medical applications [6].

Magnetron sputtering is based on the vaporization of a target material by low-pressure plasmas. The vaporized material condensates onto the coated part (substrate). A schematic view of the magnetron sputtering process is presented in Fig. 1.

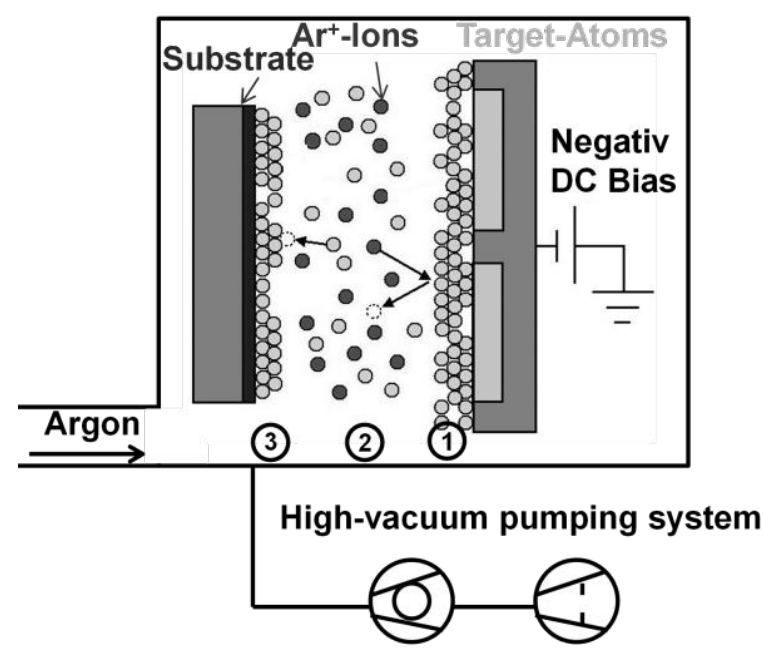

Fig. 1. Sketch of a magnetron sputtering unit. 1) Bombardment of the target with positive argon ions by means of a lowpressure plasma and sputtering of the superficial atoms of the target. 2) Transport of the sputtered atoms through the chamber. 3) Deposition of target atoms on the substrate.

As illustrated in Fig. 1 the magnetron sputtering process is carried out in a vacuum chamber. Chemically inert working gases such as argon or other noble gases are introduced into the vacuum chamber. Typical working gas pressure is about $10^{-3}$ mbar. The targets are connected to an electric generator (direct current for DC magnetron sputtering) and are negatively biased. The vacuum chamber and the substrate are electrically grounded. At the target, a glow discharge plasma consisting of positively charged argon ions and negatively charged electrons is created by collision ionization in the low pressure noble gas atmosphere. Due to the negative bias, the positive argon ions accelerate to the target and collide with the target atoms. The momentum transfer of the argon ions with the target atoms results in an ejection (sputtering) of the target atoms. The sputtered target atoms move through the chamber and condensate on the substrate and progressively form the coating.

\subsection{Magnetron sputtering process for fabrication of thin $\mathrm{Al}-\mathrm{Zr}$ foils for micro deep drawing}

A more unusual aspect of magnetron sputtering is the fabrication of metallic freestanding foils. While cold rolling is generally used to produce 15 to $30 \mu \mathrm{m}$ thick foils made of conventional materials such as pure or low alloyed aluminium, copper or stainless steel [7], the ability to roll and form high strength materials such as aluminium-zirconium alloys in micro deep drawing is very limited. This limitation is due to the presence of ductility-reducing $\mathrm{Al}_{3} \mathrm{Zr}$ precipitates, which form already during continuous casting. Therefore, alternative methods such as magnetron sputtering were considered to manufacture thin foils of aluminium-zirconium alloys. Indeed, magnetron sputtering offers the possibility to produce supersaturated solutions which are more or less free of precipitations. The aim is to improve the ductility of these alloys and to enable a better control of the hardening process of finished parts during artificial aging.

To produce Al-Zr foils by magnetron sputtering, a mirror polished low carbon steel foil with $100 \mu \mathrm{m}$ thickness was used as substrate. This substrate foil was set to a non-moving substrate holder equipped with a temperature control system. The distance between the target and the substrate was $50 \mathrm{~mm}$ and the substrate temperature was maintained at $37{ }^{\circ} \mathrm{C}$ during the deposition process. The substrate foils were coated with 20 to $30 \mu \mathrm{m} \mathrm{Al-Zr}$ using a dc magnetron sputtering unit Leybold Z700. The target consisted of a rectangular Al 4 mass $\% \mathrm{Zr}$ alloy target with dimensions of $500 \times 88 \times 10$ $\mathrm{mm}^{3}$. A flow of $100 \mathrm{sccm}$ of argon was introduced into the chamber for the deposition process, resulting in a pressure of $4 \times 10^{-3}$ mbar.

Some of the process parameters greatly influence the morphology and the mechanical properties of the final foils [8-9], which affects the whole process chain. In previous investigations, it was shown that the target power is a particularly important process parameter for the mechanical properties of the foils [8]. In this work, the influence of the target power on the whole process chain will be highlighted. Therefore, Al-Zr foils were deposited using a target power of 2 and $3 \mathrm{~kW}$ during 
respectively 2 and 1 hour so that similar thicknesses are achieved for each foil variant.

After deposition, the steel substrate was removed by chemical etching in a solution of concentrated nitric acid, resulting in the complete dissolution of the steel foils and leaving the Al-Zr foil undamaged.

\subsection{Properties of the produced Al-Zr foils}

The main properties of the Al-Zr foils produced with target powers of 2 and $3 \mathrm{~kW}$ were already studied in a previous paper establishing the relation between the target power and the hardness of sputtered Al-Zr foils [10]. In both foils studied in this work, 3.9 mass \% zirconium was measured, whereas minor traces of iron $(0.16$ mass \%) and silicon were also detected. It was verified by transmission electron microscopy (TEM) that, as expected, the foils consist of a zirconium supersaturated aluminium solution with almost no $\mathrm{AlZr}_{3}$ precipitates. The latter were only observed after aging at $400{ }^{\circ} \mathrm{C}$ and $500{ }^{\circ} \mathrm{C}$. Finally, complementary TEM examinations have shown that the density of crystal defects (dislocations) was higher in the foil sputtered at 3 $\mathrm{kW}$. This was attributed to the higher kinetic energy of the sputtered atoms at $3 \mathrm{~kW}[11]$.

\section{Mechanical testing of the foils}

\subsection{Tensile test}

Single-axis, quasi-static tensile tests were carried out for the PVD produced Al-Zr foils. An electrodynamic testing system of the type Instron ElectroPuls E1000 with an optical strain measurement based on a video extensometer [12]. The specimens were designed as rectangular flat specimens as shown in Fig. 2 (a), with the clamping ends on both sides with glued-on reinforcing steel plates to prevent failure in clamping due to the notch effect. In this way, it was possible to ensure that failure occurs almost exclusively in the test area, as shown in Fig. 2 (b).

(a)

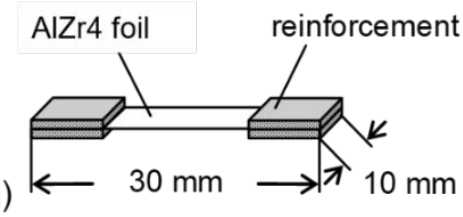

(b)

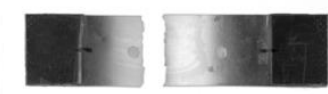

Fig. 2. Sketch of a tensile test sample (a) and tensile test specimen fractured in the test area (b).

The tensile tests were carried out under control of the strain rate which was $\dot{\varepsilon}=0.00025 \mathrm{~s}^{-1}$. Ten tests were carried out for each of the two sample batches. Fig. 3 shows a typical representative stress-strain-diagram for each of the two batches, as an example. In addition, the Hooke's straight line is drawn and parallel to it, the straight lines serving to determine the uniform elongation $A_{\mathrm{g}}$ and the elongation at break $A$. The PVD foils do not show any constriction prior to failure (see Fig. 2 (b)), so that in this case the strain at the ultimate tensile strength equals $A$. In addition, the straight line is drawn to determine the $0.2 \%$ yield strength (dashed line) $R_{\mathrm{p} 0.2}$. It can be seen that this cannot be determined with the $2 \mathrm{~kW}$ version, since the failure here already occurs at an elongation of $0.1 \%$.

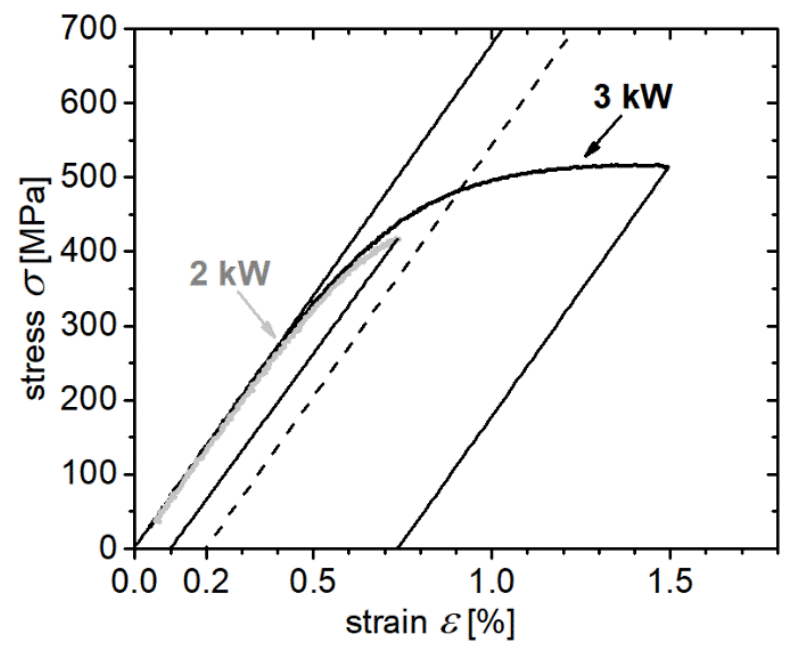

Fig. 3. Exemplary stress-strain diagrams for the two sheet metal foil batches sputtered with $2 \mathrm{~kW}$ and $3 \mathrm{~kW}$ plasma power respectively.

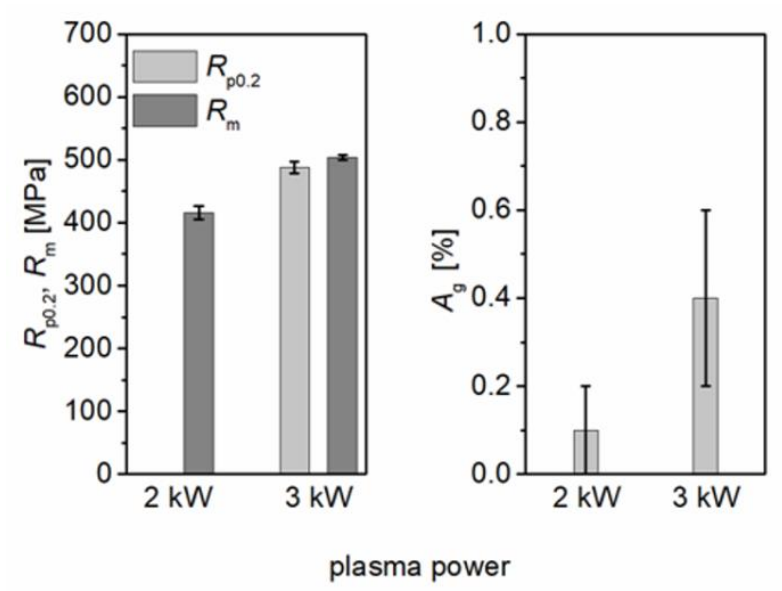

Fig. 4. Mean values of mechanical properties $0.2 \%$ yield strength, $R_{\mathrm{p} 0.2}$, tensile strength $R_{\mathrm{m}}$ and uniform elongation $A_{\mathrm{g}}$ of all valid tensile tests (as-sputtered condition).

Fig. 4 shows the results of the measured yield strength, tensile strengths and uniform elongations of 10 valid tests for each variant. Plasma power, as the only parameter varied in the manufacturing process leads to different mechanical properties. Here, the batch produced with $3 \mathrm{~kW}$ plasma power shows an approximately $88 \pm 12 \mathrm{MPa}$ higher tensile strength on average over the ten samples tested. The uniform elongation is also higher compared to the $2 \mathrm{~kW}$ sample. However, compared to conventional aluminium alloys the uniform elongation is very low at $0.1 \pm 0.1 \%$ and 0.4 
$\pm 0.2 \%$ for both variants. Thus, for the $2 \mathrm{~kW}$ sample the $0.2 \%$ yield strength could not be determined anymore. With the $3 \mathrm{~kW}$ batch, however, their mean value is $488 \pm$ $9 \mathrm{MPa}$.

The $3 \mathrm{~kW}$ variant shows significantly higher tensile strength, which is also indicated in Figure 3. The main reason for this is the increased dislocation density as shown in our previous work induced by the sputtering process at higher plasma power [11]. This observation is in conformity with hardness measurements on both variants, where the $3 \mathrm{~kW}$ charge also showed a higher hardness compared to the $2 \mathrm{~kW}$ batch [10].

\subsection{Hardness of heat treated foils}

The different $\mathrm{Al}-\mathrm{Zr}$ foils $(2 \mathrm{~kW}$ and $3 \mathrm{~kW}$ ) were annealed at $300{ }^{\circ} \mathrm{C}, 400{ }^{\circ} \mathrm{C}$ and $500{ }^{\circ} \mathrm{C}$ for 10 minutes for $1,5,10,20$ and 50 hours in order to investigate the age hardening potential of these alloys. The selected range of temperatures is in the typical range of temperatures for ageing treatment of Al- $\mathrm{Zr}$ alloys of 375 to $425{ }^{\circ} \mathrm{C}$ [13]. All ageing experiments were carried out in standard air atmosphere muffle furnace.

For the hardness measurements, small pieces of the foils were embedded in a polymer matrix and mechanically polished. Hardness measurements were performed on the polished cross section of each sample using a micro hardness tester (FISCHERSCOPE H100C) with a Vickers indenter. The indentation force was $5 \mathrm{mN}$ and the duration of the penetration, holding and indenter withdrawal phases was 10 seconds for each measurement.

The micro hardness results of the sputtered foils before and after ageing treatment at different temperatures against the ageing time are shown in Figure 5 and 6.

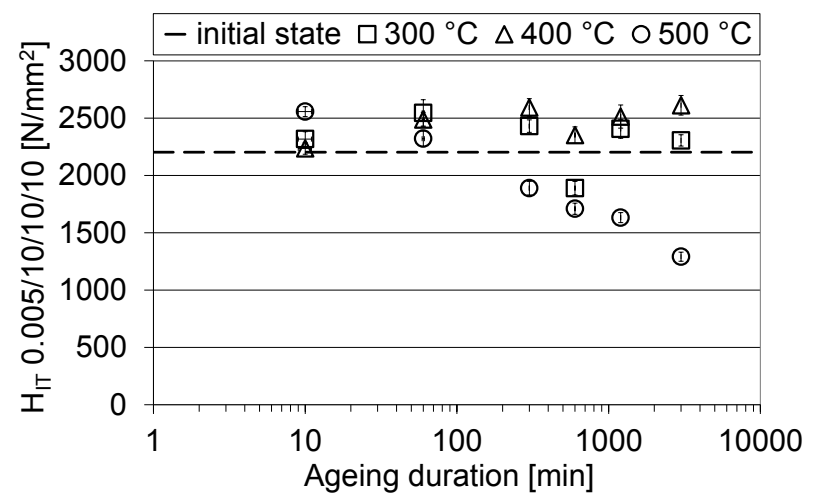

Fig. 5. Micro hardness measurements on the $\mathrm{Al}-\mathrm{Zr}$ foils produced with $2 \mathrm{~kW}$ plasma power before and after several ageing treatments between 300 and $500{ }^{\circ} \mathrm{C}$ and 10 minutes to 50 hours.

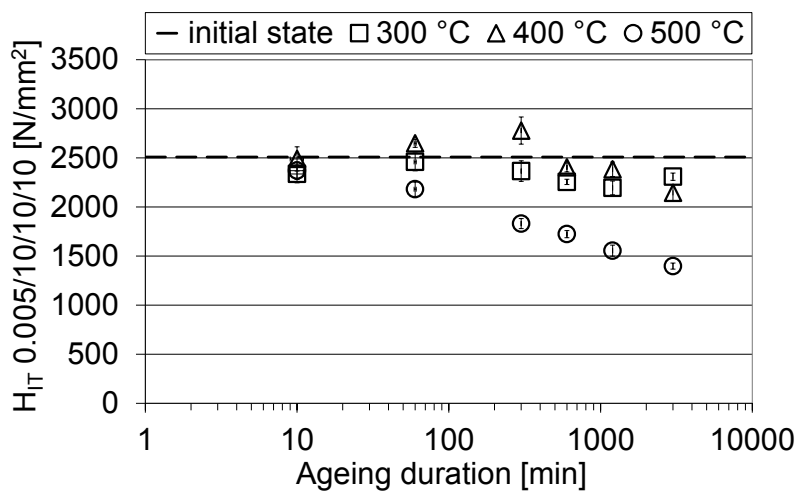

Fig. 6. Micro hardness measurements on the Al-Zr foils produced with $3 \mathrm{~kW}$ plasma power before and after several ageing treatments between 300 and $500{ }^{\circ} \mathrm{C}$ and 10 minutes to 50 hours.

In the initial state without ageing treatment, the hardness of the $2 \mathrm{~kW} \mathrm{Al-Zr}$ foils is lower $\left(\mathrm{H}_{\mathrm{IT}} \approx 2200\right.$ $\mathrm{MPa}$ ) than the hardness of the Al-Zr foils produced with a plasma power of $3 \mathrm{~kW}\left(\mathrm{H}_{\mathrm{IT}} \approx 2500 \mathrm{MPa}\right)$. The hardness of the $2 \mathrm{~kW}$ films increases during heat treatment. Thus, the experiments at $500{ }^{\circ} \mathrm{C}$ and shortest ageing time of $10 \mathrm{~min}$ lead to the maximum hardness of $\mathrm{H}_{\mathrm{IT}} \approx 2557 \mathrm{MPa}$. The ageing time of more than 10 hours does not increase the hardness at all tested temperatures. As Fig. 6 shows, a heat treatment does not lead to higher hardness anymore if foils are produced with $3 \mathrm{~kW}$ plasma power. An increasing plasma power in the sputtering process induces a higher density of crystal defects (dislocations) in the material. Hence, the hardness of the foils after the ageing treatment is the result of two superimposing mechanisms: recovery and precipitation hardening. The absence of the hardness increase during heat treatment of foils sputtered with 3 $\mathrm{kW}$ can be explained by the rapid recovery and the resulting loss of hardness (due to an accelerated heal up of the higher crystal defect density), which could not be compensated by the formation of precipitates within the investigated time and temperature range [10].

\section{Micro deep drawing of $\mathrm{Al}-\mathrm{Zr}$ cups}

Micro deep drawing is an efficient cold sheet forming process for the mass production of hollow microscopic parts with complex shape, which are widely used in micro system technologies (MST) and micro electromechanical systems (MEMS) such as connector pins, resistor caps, lead chip frames or parts of pressure sensors [14]. The principle of a micro deep drawing process is illustrated in the sketch on Fig. 7. A circular foil portion (blank) is drawn into the cavity of a die by a punch applying a force to the blank body, resulting in a 3-dimensional hollow part which has the shape of a cup. At first, the punch force is transmitted to the workpiece bottom and afterwards to the cup walls and the flanges, where the tangential stress may cause wrinkling of the blank material. To avoid this, the flanges are compressed between a blankholder and the die upper part. A strict control of the blankholder force is necessary for 
successful drawing. Indeed, if this force is too low, wrinkling occurs, whereas if the blankholder force is too high, the blank may be totally clamped by the blankholder and the blank bottom almost immediately fractures due to the rapidly increasing strain hardening caused by the punch force. Another very important process parameter, which defines a suitable process window, is the drawing ratio that is defined as the ratio of the blank radius to the punch radius. If the drawing ratio is too high, the bottom of the workpiece fails due to hardening in the cup wall area. The maximum achievable drawing ratio (without bottom fracture and wrinkling) is called limit drawing ratio and is characteristic of the formability of the foil material. This is however a simplified view and other parameters such as the foils mechanical and tribological properties, the lubrification conditions and the tool geometry must be considered. At this point of the description, micro deep drawing is similar to conventional (macroscopic) deep drawing, the only difference can be seen in the microscopic dimensions of the punch and tool (less than $1 \mathrm{~mm}$ ) and the smaller thickness of the foil (typically 15 to $50 \mu \mathrm{m})$. This small foil thickness results in structural, mechanical and tribological size effects [15], which considerably reduce the formability of micro parts compared to macroscopic parts [16].

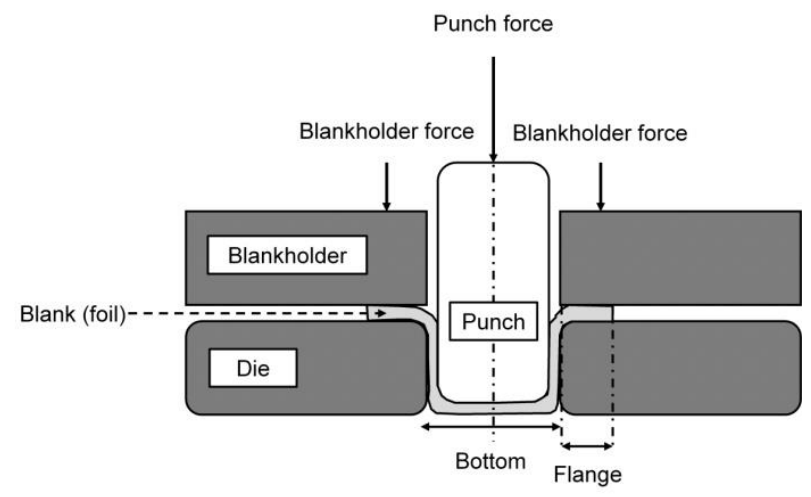

Fig. 7. Schematic of the micro deep drawing process

For the micro deep drawing of $\mathrm{Al}-\mathrm{Zr}$ foils, the drawing process was carried out on a single axis micro forming press that allows a maximum force of $500 \mathrm{~N}$. The punch force was measured using a piezo load cell of type Kistler 9217A with an accuracy of $0.01 \mathrm{~N}$. The punch velocity was kept constant at $10 \mathrm{~mm} / \mathrm{s}$, and $\mathrm{HBO}$ 947/11 was used as lubricant. Several circular blanks were cut using a picoseconds pulsed laser with a wavelength of $1030 \mathrm{~nm}$. The blanks were positioned on the die using a pneumatic gripper driven on a linear drive cross table. The position of the blank from the center of the die was measured using a CCD camera of type Allied Vision G 917 B with magnification of 0.75 , which enables blank positioning within a radius of maximum $10 \mu \mathrm{m}$ from the die center. The punch was made of a powder metallurgical tool steel of grade X135CrMoV12, and the blankholder force was always kept constant at 7 N. All relevant tool dimensions were measured using a Keyence VK 9700 laser scanning microscope. The tool dimensions are summarized in Table 1.
Table 1. Dimensions of the tool used for the micro deep drawing of Al-Zr blanks.

\begin{tabular}{|l|c|}
\hline Punch diameter $[\mathrm{mm}]$ & 1.005 \\
\hline Punch radius [mm] & 0.12 \\
\hline Drawing die diameter [mm] & 1.06 \\
\hline Average drawing die radius [mm] & 0.077 \\
\hline Drawing gap $[\mathrm{mm}]$ & 0.028 \\
\hline
\end{tabular}

Several blanks were cut from the Al-Zr foils sputtered at $2 \mathrm{~kW}$ with different diameters so that cups with different drawing ratios between 1.5 and 1.8 could be drawn. Post-drawing observations of the cup revealed that the maximum drawing ratio at which no wrinkling and bottom failure occurs (e.g. limit drawing ratio) is 1.7 as depicted in Fig. 8. This limit drawing ratio is similar to the limit drawing ratio found for commercial A199.5 foils [17], which shows that the drawability of sputtered aluminium zirconium foils is as high as the formability of pure aluminium.

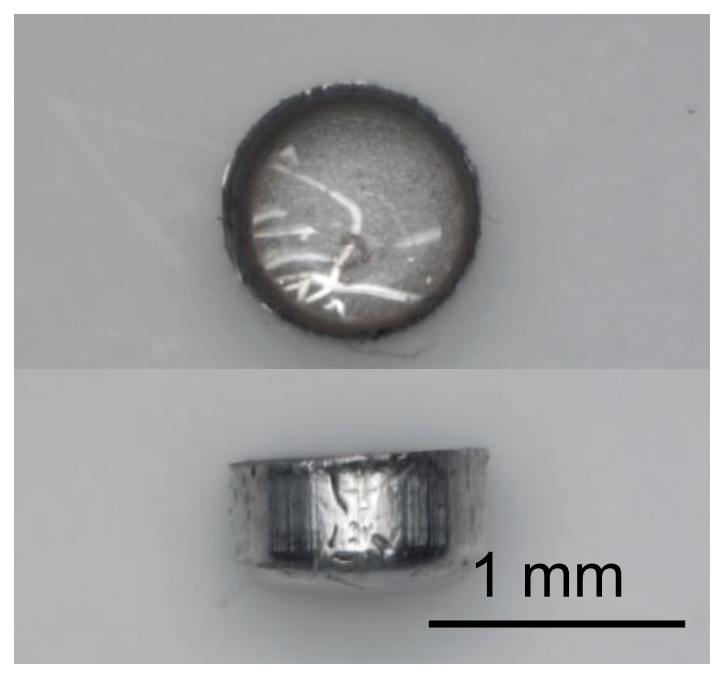

Fig. 8. Overview and side view of a deep drawn cup of aluminium zirconium with a drawing ratio of 1.7 (foils sputtered with $2 \mathrm{~kW}$ target power).

\section{Heat treatment of the cups}

Heat treatment was performed on deep drawn cups (sputtered with $2 \mathrm{~kW}$ ) with a drawing ratio of 1.5 . The experiments were carried out in two furnaces. One part of the cups was fed into the drop-down tube furnace (Fig. 9) at $500{ }^{\circ} \mathrm{C}$ and $600{ }^{\circ} \mathrm{C}$. Measurement of the drop time was performed by an area laser light measuring system at the bottom of the furnace [18]. Another part of the cups was aged in a standard air atmosphere muffle furnace at $500{ }^{\circ} \mathrm{C}$ and $600{ }^{\circ} \mathrm{C}$ for 5 minutes. After ageing, the cups were embedded and micro hardness measurements were performed as described above. 


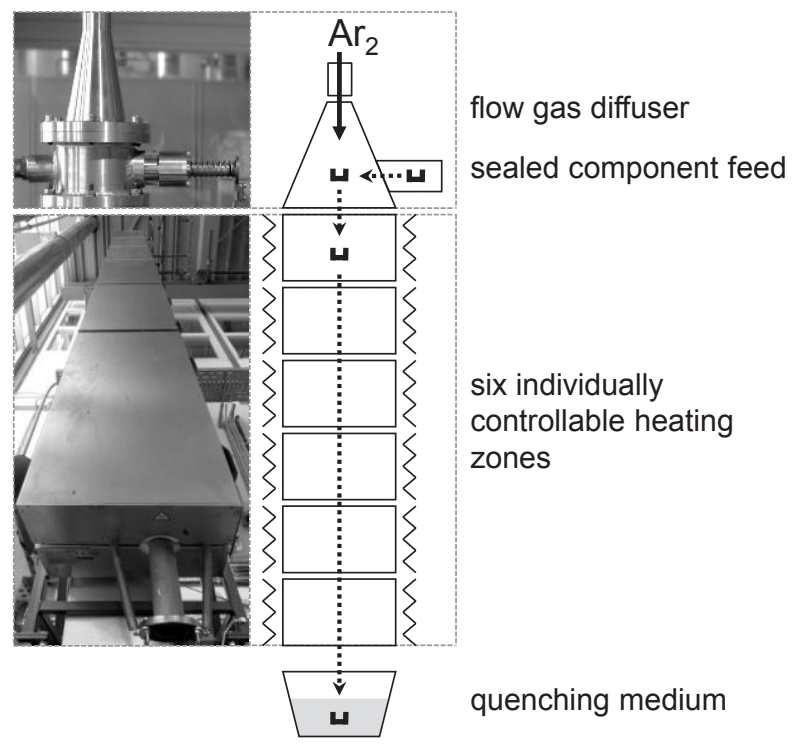

Fig. 9. Drop-down tube furnace.

Fig. 10 shows the results of the micro hardness measurements of the micro cups with a drawing ratio of 1.5 before and after heat treatment. The short-time heat treatment increased the hardness of the parts from HIT $\approx$ $2290 \mathrm{MPa}$ to HIT $\approx 2720 \mathrm{MPa}$. Thus, after about 4 seconds, the same hardness could be achieved in the drop-down tube furnace as after 5 minutes in a muffle furnace.

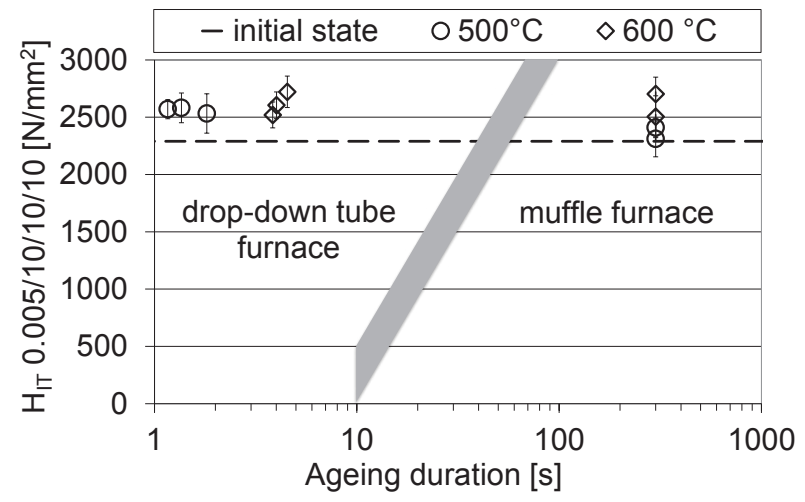

Fig. 10. Micro hardness measurements on deep drawn cup of $\mathrm{Al}-\mathrm{Zr}$ (sputtered with $2 \mathrm{~kW}$ ) with a drawing ratio of 1.5 before and after ageing treatments at 500 and $600{ }^{\circ} \mathrm{C}$ in drop-down tube furnace and standard air atmosphere muffle furnace.

The variation of the values for the fall duration of the cups is related to the different flow characteristics of the parts depending on their orientation when falling. This leads to the different drag coefficient and thus, to a change in the fall velocity and fall path.

The hardness of the cups after cold forming is about $\mathrm{H}_{\mathrm{IT}} \approx 2290$. This is nearly $100 \mathrm{MPa}$ higher than the hardness of the semi-finished foils produced with $2 \mathrm{~kW}$ target power. After short-time heat treatment, the hardness of the deep drawn cups is also higher than the hardness of the aged foils. This increase can be traced back to strain hardening during forming.

\section{Recent evolution of the fabrication of hardenable aluminium alloy foils by sputtering}

As shown by the previous results, sputtered Al-Zr foils are promising for deep drawing of hardenable micro components. Nevertheless, further improvements in terms of hardness and formability are possible by optimizing the material composition and design and the sputtering technology. Some aspects, which are currently employed to improve the properties of sputtered Al-Zr foils are briefly presented in the subsequent sections. More detailed results will be published later.

\subsection{Aluminium-scandium-zirconium alloys}

It has been reported by several authors that the addition of zirconium into aluminium-scandium alloys enhanced their mechanical properties $[1,13]$. In this context, a higher hardness was reported for Al-Sc-Zr than in both $\mathrm{Al}-\mathrm{Sc}$ and Al-Zr alloys [13]. Hence, when zirconium is added to aluminium-scandium alloys, a small amount of zirconium is incorporated into $\mathrm{Al}_{3} \mathrm{Sc}$ precipitates. The lattice constant of the newly formed $\mathrm{Al}_{3}\left(\mathrm{Sc}_{1-\mathrm{x}} \mathrm{Zr}_{\mathrm{x}}\right)$ precipitates decreases with growing zirconium content (up to $\mathrm{x}=0.5$ ) and the misfit between the precipitates and the matrix is lower, which (for a given precipitate size) enhance the coherency of the precipitates [19]. The other interesting effect of the addition of zirconium to Al-Sc alloys is the decrease of the coarsening rate of the precipitates during heat treatment and a higher recrystallization temperature [20], which is related to the slower diffusivity of zirconium in aluminium [21]. Altogether, the lower size of the precipitates, their high dispersivity and their lower misfit with the aluminium matrix explain the higher hardness of Al-Sc-Zr alloys.

\subsection{High Power Impulse Magnetron Sputtering (HiPIMS)}

Al-Sc-Zr foils were obtained by DC magnetron sputtering (DCMS) using an industrial sputtering unit (CemeCon CC800/9) equipped with 4 targets and a rotating substrate table, which enables the deposition of larger foil areas and an excellent homogeneity of the foil thickness. However, the foils presented a porous columnar structure as shown in Fig. 11a. These porosities are due to the rotating substrate table. Indeed, with this configuration the average kinetic energy of the sputtered atoms is lower than for non-moving substrate since the substrate not always faces toward target during the deposition process. Consequently, the sputtered atoms hit the coating with lower kinetic energy and the impulse driven mobility of the coating atoms is reduced, resulting in a growth process dominated by shadowing effects [22]. In order to get a denser structure, it is necessary to increase the kinetic energy of the sputtered atoms, which can be achieved by either increasing the dc target power or by using High Power Impulse Magnetron Sputtering (HiPIMS). In HiPIMS, the current applied to the target is periodical. Within a period, during the offcycle the target is not biased and within a short duty- 
cycle time, extremely high voltage is applied to the target, resulting in a higher degree ionisation than in dc sputtering and higher peak power (10 to a few hundreds of $\mathrm{kW}$ ). This leads to a higher kinetic energy of the sputtered atoms resulting in a higher mobility of the coating atoms, which reduces the formation of pores [23]. Fig 11 shows the film morphology of Al-Sc-Zr foils deposited by DCMS (Fig. 11a) and by HiPIMS (Fig. 11b). The results in Fig. 11 indicate that the foils deposited by HiPIMS have less and smaller pores compared to the foils deposited by DCMS. In terms of mechanical properties, the higher density of the HiPIMS foils results in foils with much better ductility as shown in the tensile test curves in Fig. 12. Accordingly, a higher limit drawing ratio of 1.8 was also obtained when HiPIMS Al-Sc-Zr foils were tested in micro deep drawing.

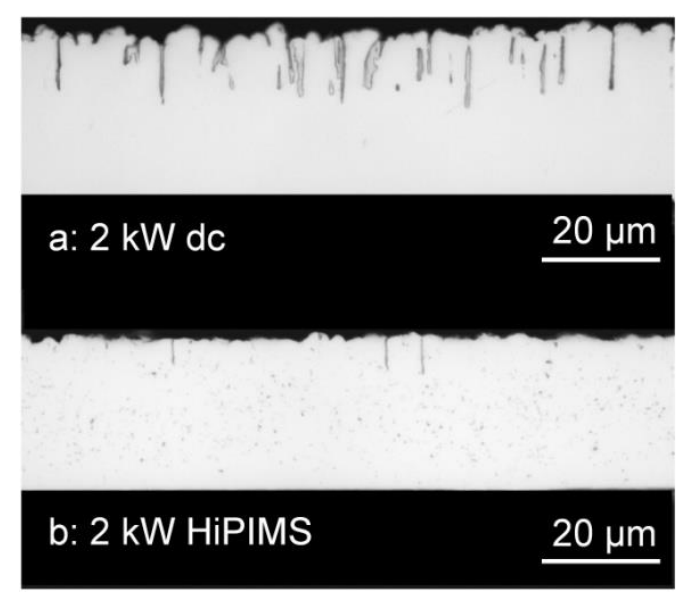

Fig. 11. Optical microscopy pictures of the cross section of two different sputtered Al-Sc-Zr foils. a: $2 \mathrm{~kW}$ dc b: $2 \mathrm{~kW}$ HiPIMS frequency $1000 \mathrm{~Hz}$ duty cycle $20 \%$.

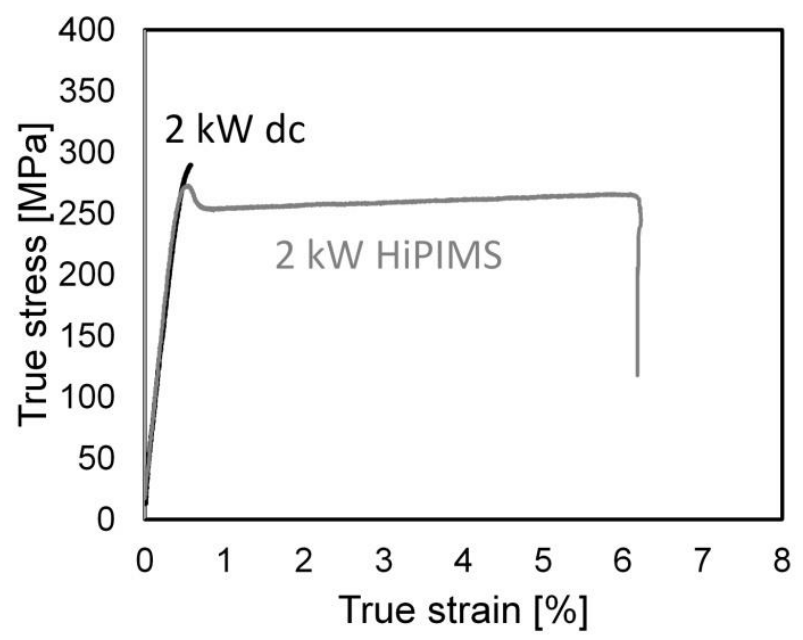

Fig. 12. Tensile test curves of a $2 \mathrm{~kW}$ DC sputtered Al $1.8 \%$ $\mathrm{Sc} 0,3 \% \mathrm{Zr}$ foil and of a $2 \mathrm{~kW}$ HiPIMS Al $1.8 \% \mathrm{Sc} 0.3 \% \mathrm{Zr}$.

\subsection{Fabrication of bimetallic Al-Sc-Zr / stainless steel foils}

Another way to improve the mechanical properties and the drawability of sputtered aluminium alloy foils is the production of bimetallic foils instead of monometallic
Al-Sc-Zr foils. Bimetallic sheets consist of a stacking of several layers of two materials, generally a hard material and a soft and ductile material as for example ultra high carbon steel and brass [24]. Similarly, aluminium / stainless steel bimetallic sheets have been produced and investigated by Lee et al. [25]. These authors have shown that the mechanical properties of bimetallic foils in tensile testing are between the mechanical properties of pure aluminium and pure stainless steel and vary proportionally to the volume fraction (i.e. the total thickness) of aluminium in the bimetallic sheets. In every case, the bimetallic aluminium / stainless steel sheets show a better strength and a better ductility than pure aluminium sheets. In deep drawing, investigations on aluminium / stainless steel bimetallic sheets have also shown that limit drawing ratios of bimetallic sheets are higher than the one of pure aluminium and that the limit drawing ratio increases with decreasing aluminium volume fraction [26]. Sputtering was used to manufacture two layers Al-Sc-Zr / X5CrNi18-10 bimetallic foils. Commercial stainless steel foils with thicknesses from 15 to $25 \mu \mathrm{m}$ were used as substrate foils. These substrate foils were coated with Al-Sc-Zr by magnetron sputtering, so that the total thickness of the bimetallic sheets was always $30 \mu \mathrm{m}$. In tensile testing (Fig. 13) these bimetallic foils showed both a better ductility and strength compared to monometallic Al-Sc$\mathrm{Zr}$ foils. The ductility and the tensile strength of the bimetallic sheets increased when the volume fraction of aluminium decreased (the volume fraction of stainless steel increases). In deep drawing as observed for thick sheets [25], the limit drawing ratio depends on the layer stacking sequence of the bimetallic foil with respect to the punch-die system. Hence, when the Al-Sc-Zr layer side was in contact with the die, bimetallic foils only achieved a limit drawing ratio of 1.7 as for pure aluminium. When the stainless steel side of the bimetallic foil faces toward the die, a limit drawing ratio of 1.9 could be achieved which is far better than the 1.7 of the Al-Zr foils presented in this paper.

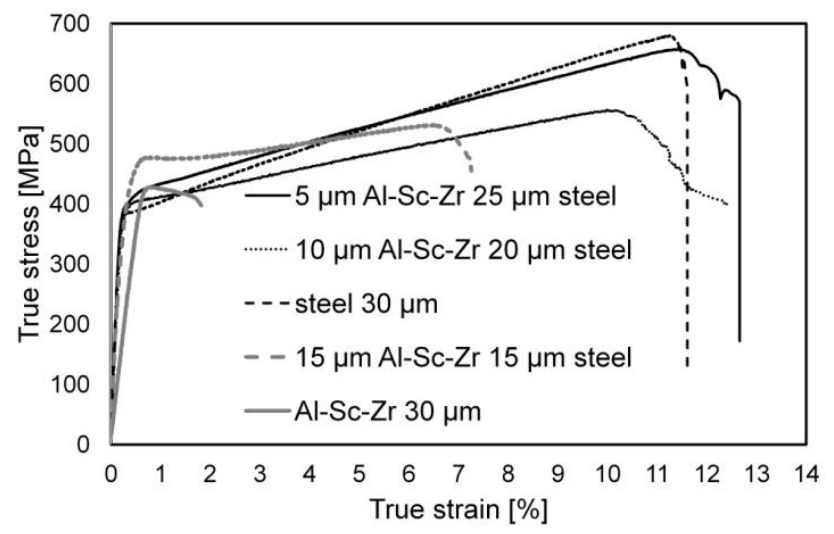

Fig. 13. Tensile test curves of a $30 \mu \mathrm{m}$ sputtered Al $1.8 \% \mathrm{Sc}$ $0,3 \% \mathrm{Zr}$ foil and of three Al-Sc-Zr / X5CrNi18-10 bimetallic foils with a total thickness of $30 \mu \mathrm{m}$ for each foil. The Al-Sc-Zr layer thickness of the bimetallic foils was $5 \mu \mathrm{m}, 10 \mu \mathrm{m}$ and 15 $\mu \mathrm{m}$ (in all foils the Al-Sc-Zr layer was sputtered at a target power of $4 \mathrm{~kW} \mathrm{dc}$ ). 


\section{Summary}

Four steps for the optimization of the process chain for the production of micro cold formed cups made of a high-strength Al-Zr alloy were presented. The influence of the parameters of the individual process steps on the mechanical properties of the deep drawn cups was investigated. Furthermore, the hardening evolution during ageing treatment of semi-finished foils and deep drawn cups was characterized. The hardening potential of the foils and the micro cups depends on the plasma power during magnetron sputtering. In addition, the maximum hardness of the cups can be increased by short-time heat treatment in a drop-down tube furnace. Improvement in terms of mechanical properties and drawability can be achieved by producing Al-Sc-Zr foils sputtered by High Power Impulse Magnetron Sputtering or by producing bimetallic foils, consisting of a Al-Sc-Zr and a stainless steel layer, instead of monolithic Al-Sc$\mathrm{Zr}$ foils.

\section{Acknowledgments}

The authors would like to thank the German Research Foundation (DFG) for financial support of the subproject A1 "PVD Sheet Metal", A2 "Heat Treatment" and B4 "Component strength" within the collaborative research centre SFB 747 "Micro Cold Forming".

\section{References}

1. J. Røyset, N. Ryum, Inter. Mater. Rev., 50, 19 (2005)

2. P. Cavaliere, Mater. Character., 57, 100 (2006)

3. J. Murray, A. Peruzzi, J.P. Abriata, J. Phase Equilib. 13, 277 (1992)

4. J. Kovac, H.-R. Stock, B. Köhler, H. Bomas, H.-W. Zoch, Surf. Coat. Tech., 215, 369 (2013)

5. G. Behrens, J. Kovac, B. Köhler, F. Vollersten, H.R. Stock, T. Nonferr. Metal Soc., 22, 268 (2012)

6. D. G. Constantin, M. Apreutesei, R. Arvinte, A. Marin, O. C. Andrei, D. Munteanu, RECENT, 12, 29 (2011).

7. G. Behrens, F. O. Trier, H. Tetzel, F. Vollertsen, J. Mat. Form 9, 253 (2015)

8. J. Kovac, H.-R. Stock, B. Koehler, H. Bomas, H.-W. Zoch, Surf. Coat. Tech., 215, 369 (2013)

9. J. Kovac, H.-R. Stock, H.-W. Zoch, Journal of Surface Engineered Materials and Advanced Technology, 2, 115 (2012)

10. A. Egorova, J. Kovac, A. von Hehl, A. Mehner, H.W. Zoch, Mat.-Wiss. u Werkstofftech., 47, 989 (2016)

11. Y. Pauleau, Residual stresses in physically vapor deposited thin films In H. S. Nalwa, Handbook of Thin Films Vol. 1 , Elsevier, Los Angeles (1992)
12. B. Köhler, H. Bomas, H.-W. Zoch, J. Stalkopf, Engineering Integrity, 31, 18 (2011)

13. K. E. Knipling, D. C. Dunand, D. N. Seidman, Acta Materialia, 56, 114 (2008)

14. Frank Vollertsen, Micro Metal Forming (Springer, Berlin, Heidelberg, 2013)

15. F. Volletsen, Z. Hu, H. Schulze Niehoff, C. Theiler, J. Mat. Proc. Tech., 151, 1 (2004)

16. F. Vollertsen, Z. Hu, J. Technol. Plast., 32, 1 (2007)

17. G. Behrens, F. O. Trier, H. Tetzel, F. Vollertsen, Int. J. Mater. Form., 9, 253 (2015)

18. R. von Bargen, A. von Hehl, H.-W. Zoch, J. Heat Treatm. Mat., 65/2, 55 (2010)

19. Y. Harada, D. C. Dunand, Mat. Sci. Eng., A329331, 686 (2002)

20. V. I Elagin, V. V. Zakharov, S. G. Pavlenko, T. D. Rostova, Phys. Met. Metall., 60, 88 (1985)

21. K. Hirano, S. Fujikawa, J. Nuc. Mater., 69-70, 564 (1978)

22. K.-H. Muller, J. App. Phys., 62, 1796 (1987)

23. K. Sarakinos, J. Alami, S. Konstantinidis, Surf. Coat. Tech., 204, 1661 (2010)

24. C. K. Syn, D. R. lesuer, J. Wolfenstine, O. D. Sherby, Met. Trans., 24A, 1647 (1993)

25. D. N. Lee, Y. K. Kim, J. Mat Sci., 23, 1436 (1988).

26. M. H. Parsa, K. Yamaguchi, N. Takakura, Int. J. Mech. Sci., 43, 2331 (2001) 